\title{
Study of Hybrid Autonomous Power System Modelling Via Multi-Agents Strategy
}

\author{
NASRI Sihem \\ Electric Systems Analysis and signals processing Unit \\ Faculty of Sciences of Tunis, Tunisia \\ BEN SLAMA Sami \\ Information System Department \\ King Abdulaziz University, Jeddah, Saudi Arabai
}

\author{
ZAFAR Bassam \\ Information System Department \\ King Abdulaziz University, Jeddah, Saudi Arabai \\ CHERIF Adnan \\ Electric Systems Analysis and signals processing Unit \\ Faculty of Sciences of Tunis El Manar, Tunisia
}

\begin{abstract}
In this paper, a design of a Hybrid autonomous Power System is proposed and detailed. The studied system integrates several components as solar energy source, Energy Recovery system based on a proton membrane exchange fuel cell system and two energy storage components, namely, (1) Energy Storage based on $\mathrm{H} 2$ gas production, and (2) an Ultra-capacitor storage device. The system is controlled through an energy management Unit which aims to ensure the smooth operation system to be against any unexpected fluctuation. The modelling of the system relies on the application of a multi-agent strategy whose good effects on the performance of the system is evaluated and demonstrated by the obtained simulation results. The improvement of the system performance is proved through a comparison with the conventional strategies. The system that relies on multi-agents control approach seems to be more reliable and promising in term of effectiveness and fast response.
\end{abstract}

Keywords-Solar Source; Energy Recovery; Hydogen; Energy Storage; Ultra-capacitor; Multi-agent; Energy Management

\section{INTRODUCTION}

Recourse to the use of renewable energies becomes a necessity in view of the extravagant consumption of fossil energy (coal, oil, natural gas, uranium, etc.) which presents harmful effects on the environment such as the release of carbon dioxide $(\mathrm{CO} 2)$ and the emission of greenhouse gases that affect the global climate balance.

The renewable energy resources appear to be a promising replacement to the exhaustible natural resources. Thus, its clean, efficient and vital characteristics make them of great importance. However, the direct vulnerability of this type of energy sources to climate change cannot be ignored. For this, the hybridisation between different energy sources and the use of storage devices can help reducing the problem of intermittency related to these resources. Integrating hydrogen storage device in renewable energy system has considered as an additional backup application that proves its performance in many applications such as remote areas, transportation and energy building. Compared to commonly used battery storage, hydrogen is well suited for seasonal storage applications, as it is easy to be installed anywhere [1]. In addition, hydrogen can easily be converted into electricity through fuel cell technology, particularly the proton membrane exchange, which must be a promising energy source for building sustainable, Environment [2]. But, the fuel cell complains of a slow dynamics problem related to the constant time of the hydrogen. So, the integration of Ultra-capacitor Storage (USC) seems indispensable to supervise the behaviour of the Fuel cell [3]. Thus, the incorporation of the USC will allow the system to track rapidly changing charges while allowing the fuel cell to respond at a slower pace and may reduce the frequency deviations.

Several worldwide studies were shown interest in modelling, control, and management of hybrid power system based on PV source and hydrogen storage technologies.

The authors in [4], proposed a various optimal hybrid techniques to manage the HPS which includes photovoltaic, fuel cell and battery. To achieve the optimal system performance, an accurate control strategy was proposed which is characterised by the ratio of hydrogen amount with. To monitor the system performance, a practical load demand and actual meteorological data (solar irradiance and air temperature) were included. However, this work lacks of a control and management approach strategy study. It simply presents the models of the system elements and it focuses on the optimisation in the control of photovoltaic module (MPPT).

In [5], the authors proposed an accurate hybrid feeding system. They used an energy management unit to control the load demand and the energy source, such as the solar photovoltaic (PV) network, the fuel cell and the battery. They integrate long-term energy storage (hydrogen $\left(\mathrm{H}_{2}\right)$ ) in the proposed system to manage the output power fluctuations. But, the system efficiency was not mentioned or treated by this work.

A hybrid system using photovoltaic panels (PV), batteries and fuel cells (FC) is presented by [6]. To effectively manage the system, several Power Management Strategies (PMS) have been implemented. The simulation results were performed using TRNSYS software and then analysed and treated. Although this work presents a comparative study between different management strategies but it focuses at the level of results on the presentation of the battery state of charge (SOC) and the hydrogen tank pressure without mentioning the parameters already described by the management algorithm. 
Referring to previous cited works, this work presents the impact of the application of multi-agents strategy to the hybrid power system which helps improving:

- The system response against any fluctuation.

- The system efficiency.

- The way of energy storage.

- The way of energy recovery.

The paper is organised as: Section 2 gives a general description of the HPS system and its components. Section 3 presents the energy management unit analysis followed by the study of the overall system efficiency. Section 4 is devoted to evaluate the obtained simulation results. Finally, a summary of the work is given in Section 5.

\section{DESCRIPTION OF THE WHOLE HPS}

In this section, a design of hybrid power system (HPS) will proposed and described. Thus, the basic elements of studied system are:

- Solar Energy Component (SEC).

- Long-term Energy Storage Component (ESC) based on electrolyser for the production of hydrogen.

- High pressure Hydrogen tank for gas storage.

- Energy Recovery Component (ERC) characterised by the use of fuel cell for energy generation through $\mathrm{H}_{2}$ gas.

- Ultra-capacitor Storage Component (USC) used for a short-lived electrical energy buffer.

The system management is ensured by a suitable algorithm that keeps the smooth system operation by satisfying the load requirements.

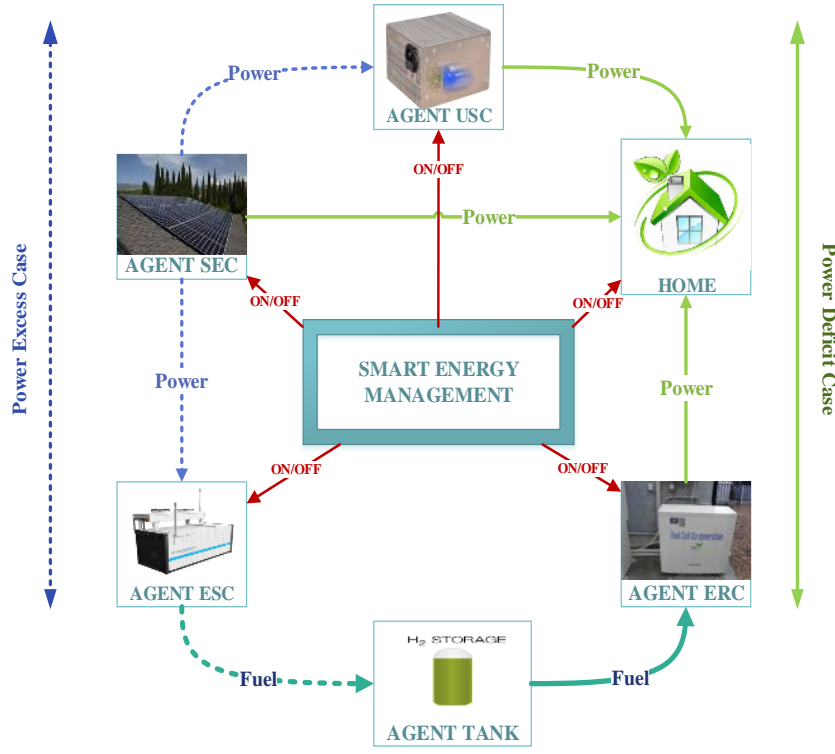

Fig. 1. Scheme of Whole HPS
Figure 1 shows the scheme of the overall HPS system. The system comprises six principle agents separated by the agent supervisor which is used to control and manage the system and ensures the communication between each agent. Thus, the agent SEC controls the power coming from the solar in order to supply a DC load and send the power to the storage components in the surplus case. The agent storage component either the ESC or USC are ready to store the excess power when they receive the decision order from the agent supervisor after the requirements analysis. At the same, both ESC and USC agents control the inlet power coming from the SEC and send the checking results to the agent supervisor. The backup system is intervening in the deficit power case. At this moment, either the agent ERC or the agent USC receives the activation order from the agent supervisor to satisfy the load demand.

\section{A. The agent SEC}

The SEC is composed of a solar conversion unit that integrates a boost converter which is controlled by a maximum power point tracker (MPPT) (see Figure 2). The SEC is assimilated by an agent in order to evaluate and control the input and output voltages and currents of the highlighted subsystem.

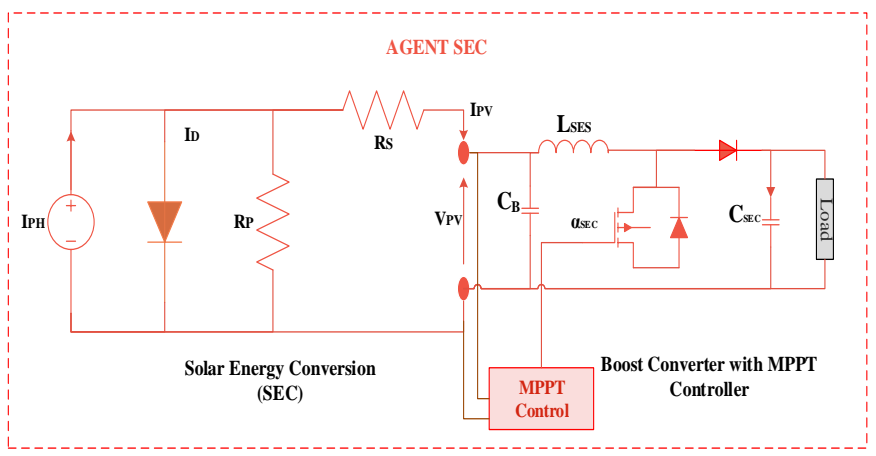

Fig. 2. Agent SEC

Hence the final output voltage that feeds the load is expressed as [7]:

$$
\left\{\begin{aligned}
V_{S E C} & =\frac{1}{1-\alpha_{S E C}} \cdot V_{p v} \\
I_{S E C} & =\frac{P_{S E C}}{V_{S E C}}
\end{aligned}\right.
$$

$\mathrm{V}_{\mathrm{SEC}}, \alpha_{\mathrm{SEC}}, \mathrm{V}_{\mathrm{pv}}, \mathrm{P}_{\mathrm{SEC}}$ and $\mathrm{I}_{\mathrm{SEC}}$ are defined as SEC output voltage, the boost duty cycle, the PV voltage, the output SEC power and current respectively.

$$
V_{p v}=\frac{N_{s} \cdot n \cdot k T}{q} \ln \left(\frac{I_{P H}-I_{p v}+N_{p} \cdot I_{s}}{N_{p} \cdot I_{s}}\right)-\frac{N_{s}}{N_{p}} \cdot R_{s} \cdot I_{p v}
$$

Where $\mathrm{N}_{\mathrm{s}}, \mathrm{N}_{\mathrm{p}}, \mathrm{n}, \mathrm{k}, \mathrm{T}, \mathrm{q}, \mathrm{R}_{\mathrm{s}}$ and $\mathrm{R}_{\mathrm{p}}$ design respectively the series and parallel number of cell, the solar ideality factor, the Boltzmann constant, the solar temperature, the electrical charge and the shunt and parallel resistances. 


\section{B. The agent ERC}

The ERC is consists of a stack of proton exchange membrane fuel cell (PEMFC) linked to DC-DC power converter. Thus, the agent ERC works as a backup system converts the inlet hydrogen amount into electricity to satisfy the load requirements. So, it aims to control the hydrogen consumption rate in order to protect the device versus any deep consumption.

Thus, the instantaneous hydrogen consumption rate can be deduced from equation (3) [8].

$$
\mathrm{Q}_{\mathrm{H} 2}^{\mathrm{C}}=\frac{\mathrm{N}_{\text {cell }}}{2 \cdot \mathrm{F} \cdot \mathrm{h}_{\mathrm{F}}^{\mathrm{ERC}}} \cdot \mathrm{I}_{\mathrm{ERC}}
$$

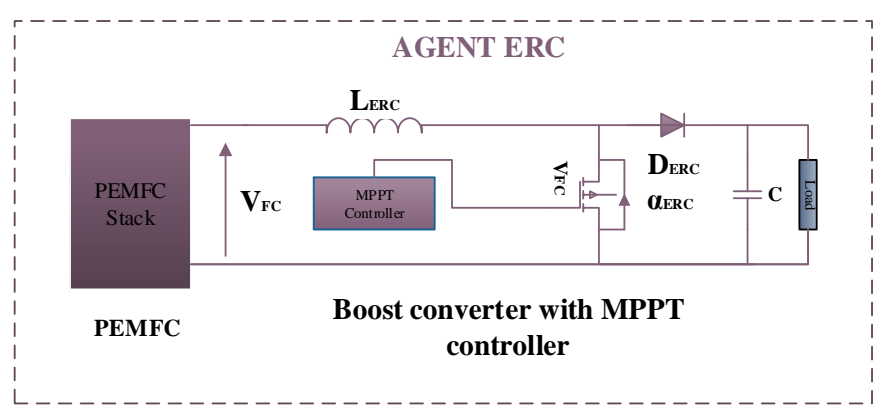

Fig. 3. Agent ERC

\section{The agent ESC}

The ESC is used to maintain the energy storage in its chemical form as hydrogen gas. It consists of a stack of a proton membrane exchange water electrolysis that generates hydrogen gas by decomposing the water molecules into hydrogen and oxygen. The hydrogen production process is ensured by the extra electric current provided by the SEC. Thus, the hydrogen production rate is expressed in the function of the electrical current in the equivalent electrolyser circuit (see, Figures 3 and 4). So, it can be defined as follows [9]:

$$
\mathrm{Q}_{\mathrm{H} 2}^{\mathrm{P}}=\frac{\mathrm{h}_{\mathrm{F}}^{\mathrm{ESC}} \mathrm{N}_{\mathrm{C}}}{2 \cdot \mathrm{F}} \cdot \mathrm{I}_{\mathrm{ESC}}
$$

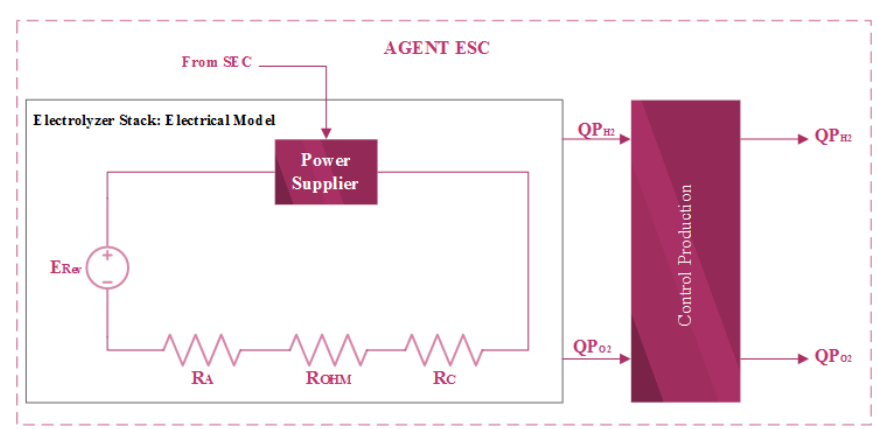

Fig. 4. Agent ESC

\section{The agent Tank}

The agent tank aims to control the inlet and the outlet hydrogen flow in high pressure tank storage. Indeed, the required hydrogen quantity is sent directly from the ESC to ensure the required ERC hydrogen amount. The stored hydrogen quantity, sent to the storage tank, presents the remaining amount of hydrogen which is defined by the difference between hydrogen produced and consumed. Thus, the dynamics of the tank storage is obtained as follows [10]:

$$
\mathrm{P}_{\mathrm{T}}-\mathrm{P}_{\mathrm{Ti}}=\mathrm{z} \frac{\mathrm{Q}_{\mathrm{H} 2}^{\mathrm{IN}} \mathrm{RT}_{\mathrm{T}}}{\mathrm{M}_{\mathrm{H} 2} \mathrm{~V}_{\mathrm{T}}}
$$

\section{E. The agent USC}

The Ultra-capacitor Storage Component (USC) is used as short-term energy storage to maintain the energy distribution process during peak powers event. Indeed, the USC presents two different statuses: charge and discharge. The USC is used as energy storage when the SEC generates an exceeded power when there is an interruption of the hydrogen production process: charge mode. However, it is applied as a backup system when the power, sent from the SEC and the ERC, seems insufficient to ensure the requirements: discharge mode. The USC agent controls its internal behaviour through the state of charge (SOC) index in order to prevent the USC from overloading and under loading [11]. The state of charge of the USC can be deduced from the equation below.

$$
\mathrm{SOC}_{\mathrm{USC}}=\frac{\mathrm{V}_{\mathrm{USC}^{2}}^{2}}{\mathrm{~V}_{\mathrm{USC}_{\max }}^{2}}
$$

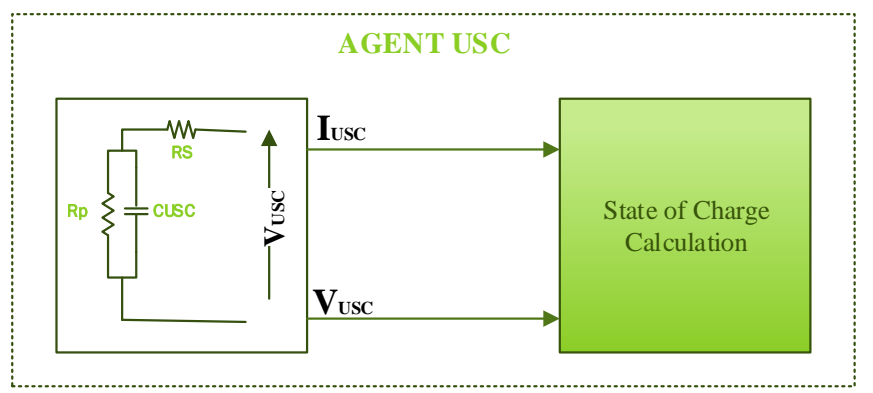

Fig. 5. Agent USC

Where; $\mathrm{V}_{\text {USC }}$ and $\mathrm{V}_{\text {USCmax }}$ are defined as the USC voltage and the USC maximum voltage respectively. Hence, the USC voltage can be deduced referring to the electric model of the USC given by Figure 5 [12]. So, it can be expressed as:

$$
\mathrm{V}_{\mathrm{USC}}=\mathrm{R}_{\mathrm{S}} \mathrm{I}_{\mathrm{USC}}+\frac{1}{\mathrm{C}} \grave{0}_{0}^{\mathrm{t}}\left(\mathrm{I}_{\mathrm{USC}}-\mathrm{I}_{\mathrm{USC}}^{\mathrm{DH}}\right) \cdot \mathrm{dt}+\mathrm{V}_{\mathrm{USC}}(0)
$$

\section{F. The agent Load}

The load agent is presented to inform about the power demands especially the current load power fluctuation.

$$
\mathrm{I}_{\text {Load }}=\frac{\mathrm{P}_{\text {Load }}}{\mathrm{V}_{\text {Load }}}
$$

\section{G. The agent Supervisor}

The agent supervisor is the main agent responsible for taking the decision required. By identifying the demands of the load energy, this agent determines its functioning nature: 
Mode1: Energy storage

Mode2: Energy recovery

The working of this agent is detailed in the next section.

\section{ENERGY MANAGEMENT APPROACH}

Our work is specialised by a new energy management approach which is based on a multi-agent technique. This approach can be classified as an intelligent method used to manage the recovery and the storage of the energy. The agents move from one state to another based on actions occurring in the environment or to the messages received. Each agent changes its behaviour from one state to another and this, according to the interactions produced between the system agents or as a function of time response constraints associated with transitions.

\section{A. Algorithm of system management}

The energy management approach is characterised by several states $\{\mathrm{S} 1 \ldots \mathrm{S} 6\}$ (see, Figure 6). In addition, the transition from one state to another is carried out through the verification and the validation of the related conditions.

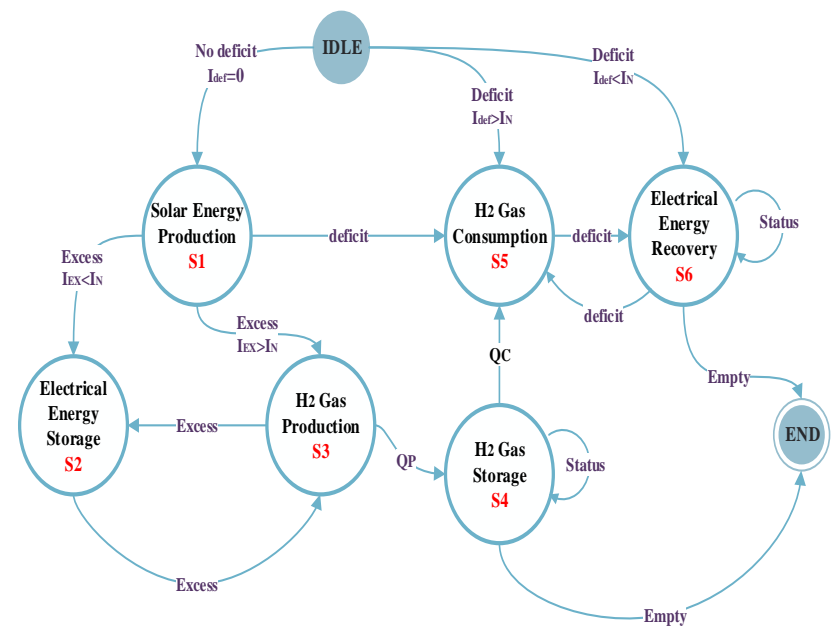

Fig. 6. State Diagram of HPS

So, the behaviour of the control strategy can be given by the algorithm described (also see, Figure 7).

\section{- Algorithm of system functioning:}

: Idle: Startup the system

Mode1: $\mathrm{T}_{\mathrm{M1}}: \mathrm{I}_{\mathrm{def}}=0$

$\mathrm{S}_{1}$ : Solar Energy Production

$\mathrm{T}_{1}: \mathrm{I}_{\mathrm{EX}}<\mathrm{I}_{\mathrm{N}}$

$\mathrm{S}_{2}$ : Electrical energy storage $\left(\mathrm{D}_{\mathrm{USC}}=1\right)$

$\mathrm{T}_{2}: \mathrm{SOC}_{\mathrm{USC}}=1 \| \mathrm{I}_{\mathrm{EX}}>\mathrm{I}_{\mathrm{N}}$

$\mathrm{S}_{3}: \mathrm{H}_{2}$ gas production $\left(\mathrm{D}_{\mathrm{ESC}}=1\right)$

$$
\mathrm{T}_{3}: \mathrm{SOC}_{\mathrm{H} 2}<1
$$

$\mathrm{S}_{4}: \mathrm{H}_{2}$ gas Storage

Mode2: $\mathrm{T}_{\mathrm{M} 2}: \mathrm{I}_{\mathrm{def}}>\mathrm{I}_{\mathrm{N}}$

$$
\begin{gathered}
\mathrm{S}_{5}: \mathrm{H}_{2} \text { gas Consumption }\left(\mathrm{D}_{\mathrm{ERC}}=1\right) \\
\mathrm{T}_{4}: \mathrm{SOC}_{\mathrm{H} 2}=0 \| \mathrm{I}_{\mathrm{def}}<\mathrm{I}_{\mathrm{N}}
\end{gathered}
$$

$\mathbf{S}_{6}$ : Electrical energy Recovery $\left(\mathrm{D}_{\mathrm{USC}}=1\right)$

$$
\mathrm{T}_{5}: \mathrm{SOC}_{\mathrm{USC}}=0 \& \& \mathrm{SOC}_{\mathrm{H} 2}=0
$$

End: System Shutdown

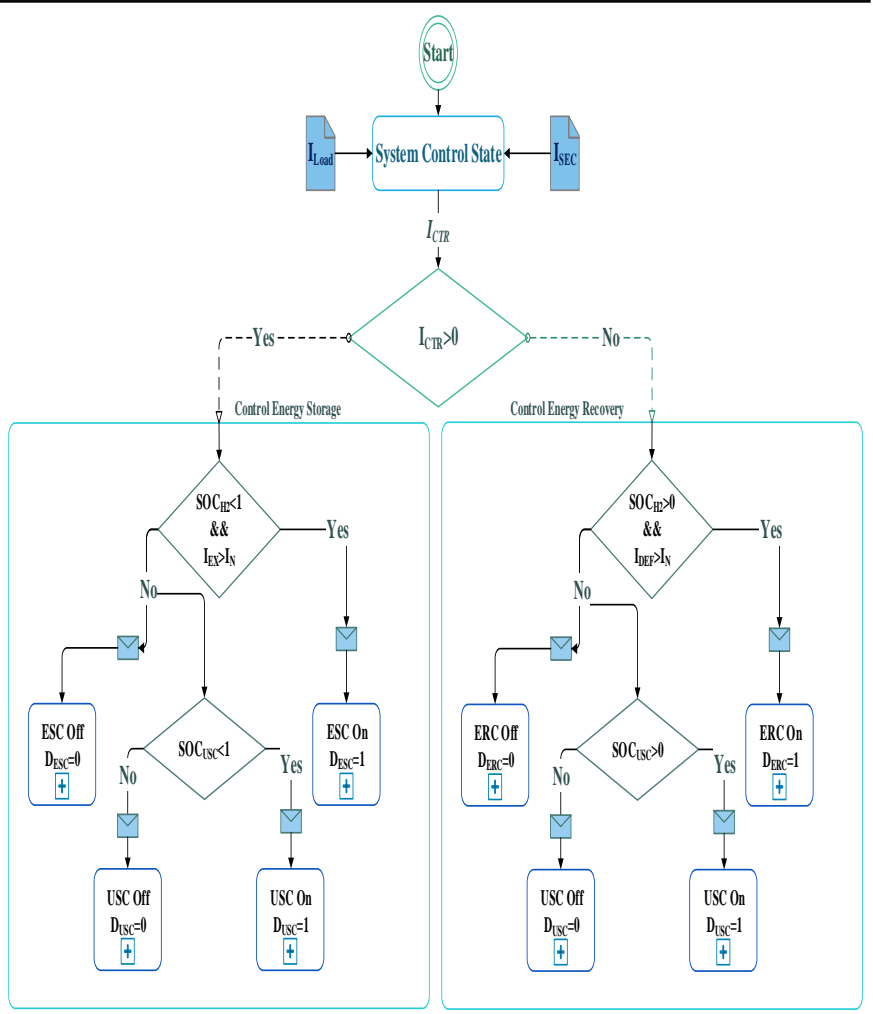

Fig. 7. Algorithm of system decision 
TABLE I. S SYSTEM COMPONENTS PER MODE

\begin{tabular}{|l|l|l|l|l|l|}
\cline { 2 - 5 } \multicolumn{1}{c|}{} & \multicolumn{4}{l}{ Highlighted Components } & \multicolumn{1}{l}{} \\
\hline Mode & k=1 & k=2 & k=3 & k=4 & Number of Ways \\
\hline 1 & SEC & USC & ESC & Tank & N=4 \\
\hline 2 & SEC & USC & ERC & Tank & N=4 \\
\hline
\end{tabular}

Where $I_{E X}, I_{N}$ and $I_{\text {def }}$, present respectively the excess power current, the nominal functioning current of both electrolyser and fuel cell and the deficit power current.

It should be noted that, the system will be well sized to obey to the conditions imposed by the control algorithm. If appropriate (no electricity provided by the SEC (no solar radiation)), the system in this case will integrate an additional renewable source (wind turbines for example) to alleviate the problem of electricity insufficiency.

\section{B. Efficiency calculation}

In general, the overall efficiency relies on the applied control approach followed by the system. Usually, the system efficiency is given by the product of the partial efficiency of all constitutive subsystems which made its value fluctuating according to the energy flow circuit changes (see, Figure 8). Thus, the standard way for efficiency calculation is defined as follows:

$$
\eta_{\text {Classical_method }}=\eta_{S E C} \cdot \eta_{E S C} \cdot \eta_{T} \cdot \eta_{E R C} \cdot \eta_{U S C}
$$

The way of overall system efficiency calculation proposed by this work refers to the determination of the efficiency per mode. So, it can be defined as the production of obtained efficiency in each mode, as in Table 1:

$$
\eta_{G}=\prod_{i=1}^{n_{M}} \eta_{M_{i}}
$$

The global efficiency per mode can be expressed as:

$$
\eta_{M_{1,2}}=\frac{\sum_{i=1}^{n} w a y_{i}}{\sum_{k=1}^{N} \eta_{k}}
$$

The way efficiency is calculated from Eq.9.

$$
\text { way }_{i}=\prod_{k=1}^{N} \eta_{i, k}
$$
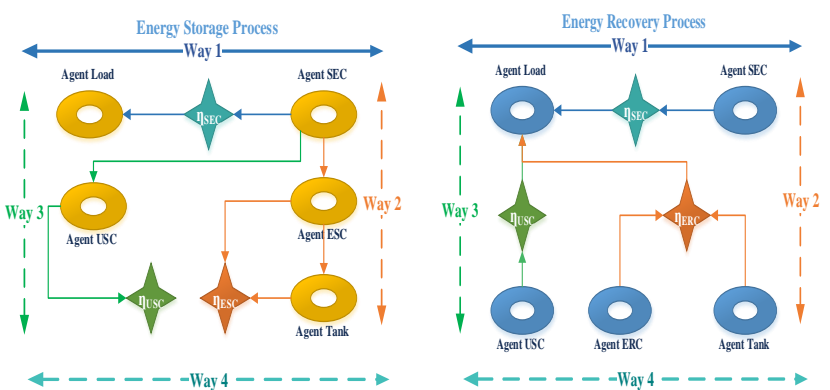

Fig. 8. Supervisory control "Mode 1, 2" efficiency calculation

\section{RESULTS AND DISCUSSION}

This section is devoted to test and to evaluate the studied system performance. So, numerous simulation results have been carried out using Matlab/Simulink environment. Additionally, the simulation test relies on several study cases as:

- The dynamical system behaviour: the use of dynamic SEC and load profiles.

- The energy storage constraint: the balance between ESC and USC.

- The energy recovery constraint: the alternation between the different power sources to maintain the load demand.

The main objective is to prove the effectiveness and robustness of the multi-agent control technique in the adaptation to any system behaviour change. In this study case, a DC load profile is chosen to test and treat the system behaviour (see, Figure 9).
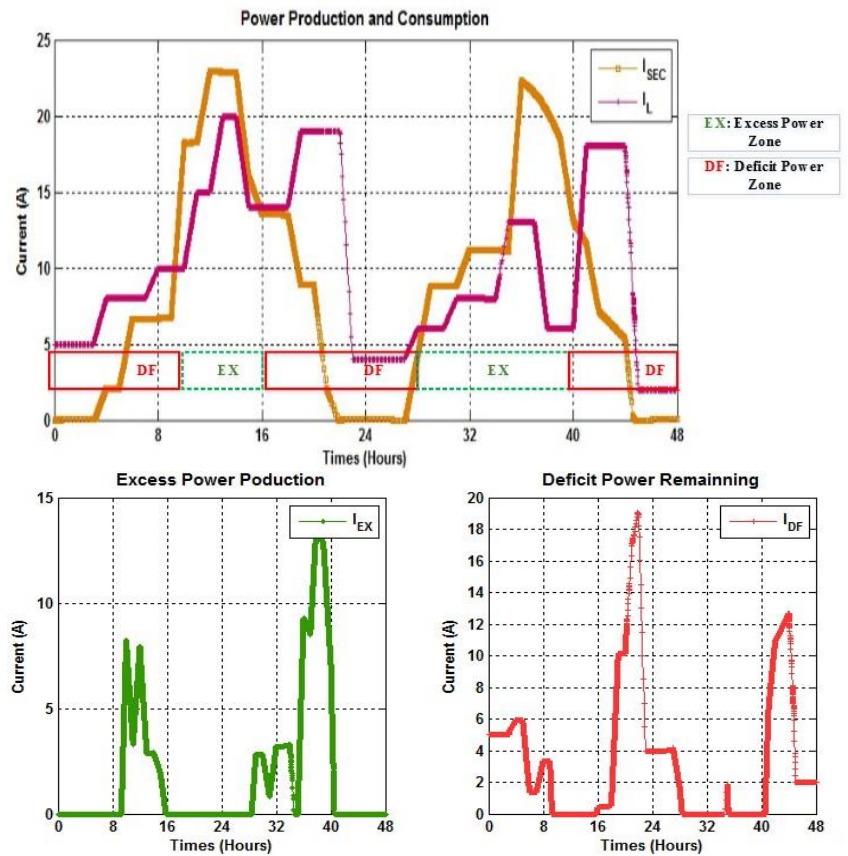

Fig. 9. The control of energy 
The SEC presents the main energy source which has priority to meet the load requirements. Thus, the energy production from SEC must be controlled to identify the system status. Thus, referring to the difference between the SEC current $\left(\mathrm{I}_{\mathrm{SEC}}\right)$ and the user demand $\left(\mathrm{I}_{\text {Load }}\right)$, we can identify either the system is under in excess or deficit power state. In this basis, two different modes have to be presented. The first mode is devoted to control the energy production and storage process. However, the second mode is dedicated to treat the deficit power case. So, two main parameters are presented to control the system behaviour and to balance from one mode to another. These parameters are the current excess $\left(\mathrm{I}_{\mathrm{EX}}\right)$ and the current deficit $\left(\mathrm{I}_{\mathrm{DF}}\right)$ (see, Figure 9). The system control is performed by the agent supervisory that is responsible for decision making.
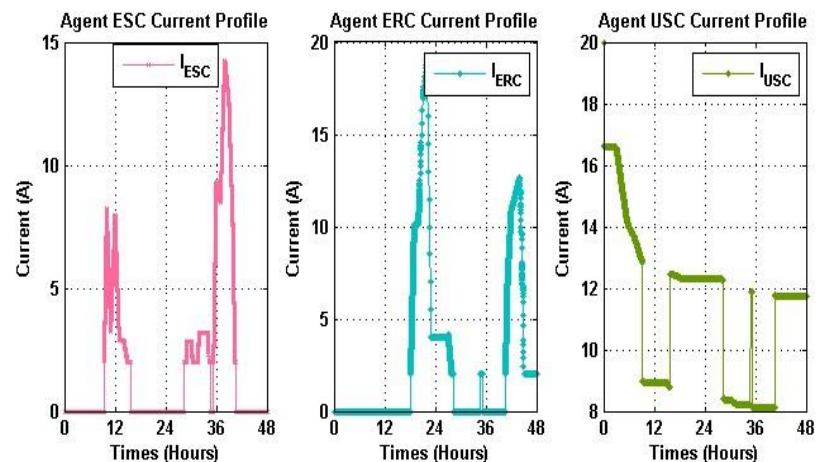

Fig. 10. ESC, ERC and USC Agents behaviour
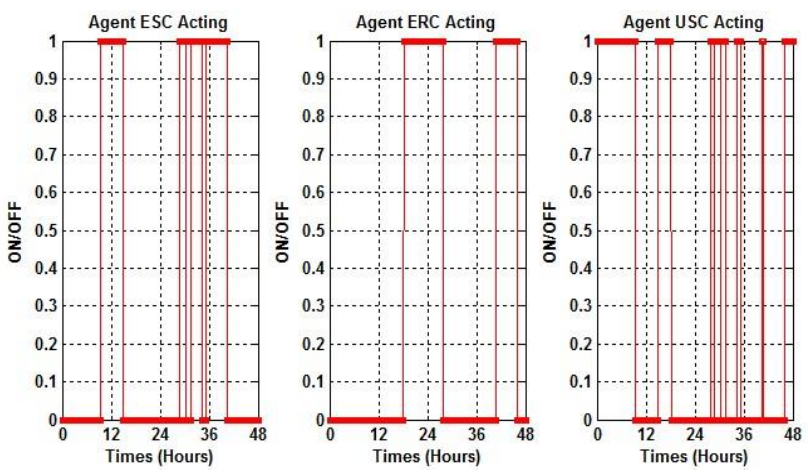

Fig. 11. ESC, ERC and USC Agents behaviour
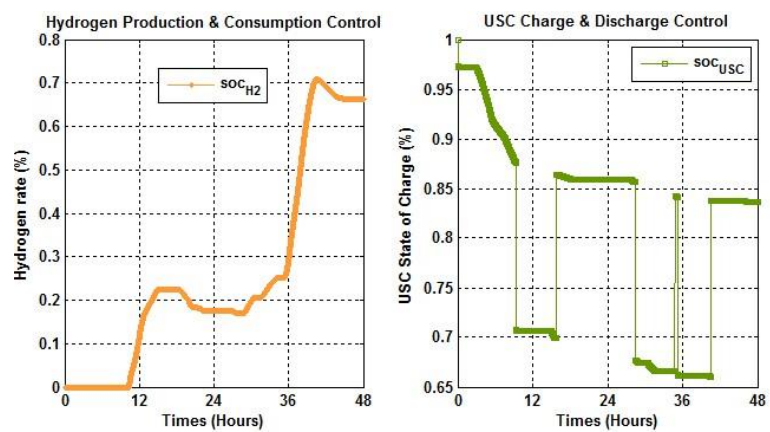

Fig. 12. Tank and USC Agents' behaviour

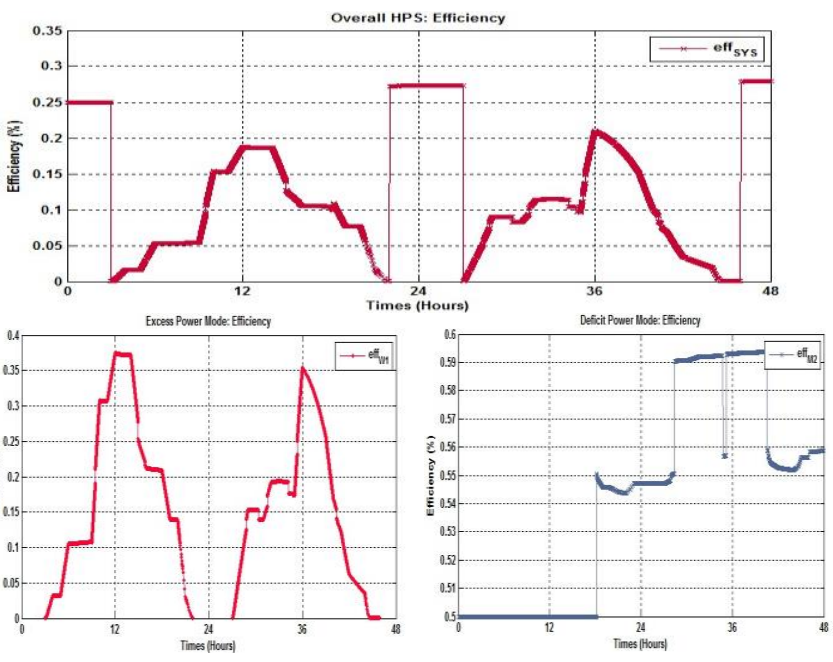

Fig. 13. Overall eficiency and mode 1,2 efficiency resulting

\section{A. Mode ' 1 ' operation}

During the simulation time test, the system undergoes several fluctuations in its behaviour. Thus, the HPS system provides an excess of power during some specific periods $([\mathbf{9 h}-\mathbf{1 6 h}]$ and $[\mathbf{2 9 h}-\mathbf{3 6 h}])$. Hence, the excess of power must be by the way controlled and stored in favourable conditions by the proper component.

Between 9h and 14h., after the checking of the ability of $\mathrm{H}_{2}$ tank to store $\mathrm{H}_{2}$ gas production and when the power reached the nominal value operated by ESC, the agent supervisor allows the production of $\mathrm{H}_{2}$ gas by activating the agent ESC (see, Figures 10 and 11). At this moment, the quantity of the hydrogen gathered in the tank grows.

Between $14 \mathrm{~h}$ and $\mathbf{1 6 h}$, we can see that the system use USC to rectify the operation of the energy storage. At this moment, the $\mathrm{H}_{2}$ production state is stopped cause of the fullness of $\mathrm{H}_{2}$ $\operatorname{tank}\left(\mathrm{SOCH}_{2}=1\right)$.

These events can be repeated in other time intervals depending on the system state.

The global efficiency, in this mode, reaches at maximum $33 \%$.

\section{B. Mode '2' operation}

During a three time intervals $[\mathbf{0 h}-\mathbf{9 h}] ;[\mathbf{1 6 h}-\mathbf{2 9 h}]$ and [40h-48h], the system complains of a power deficit that must be rapidly rectified and coved to ensure the load requirements.

Between $\mathbf{0 h}$ and $\mathbf{9 h}$, the system has recourse to the USC to cover the energy needed when the ERC is disabled cause of the insufficient quantity of $\mathrm{H}_{2}$ gas presented in the tank (see, Figure 12). At this moment, the USC is being discharged causing the decrease of the USC state of charge ( $\mathrm{SOC}_{\mathrm{USC}}$

Between 18hand $\mathbf{2 8 h}$, the system demands to rectify the power deficit. The agent supervisor chose, this time around, the agent ERC to supply the load due to the presence of the 
satisfied amount of $\mathrm{H}_{2}$ gas $\left(\mathrm{SOCH}_{2}>0\right)$ (see, Figure 12).

The global efficiency, in this mode, reaches at maximum $60 \%$.

Finally, from the Figure 13 we can see the overall efficiency variation of hybrid power system which attains at maximum $27 \%$ thanks to the applied multi-agent strategy.

Referred to the works [13] and [14], we can deduce that the adopted management strategy treated by this paper can offer an acceptable efficiency ( $27 \%$ versus $4 \%$ using classical method). This value can be improved in other study case specifically when there is tendency to optimise the behaviour of each system element.

Another important criterion for judging the profitability and relevance of the proposed system is the simulation time. Indeed, the use of the multi-agent strategy makes it possible to reduce the execution time compared to classical strategies. Hence, the system becomes, in this case, more adaptable for real-time applications (see, Figure 14).

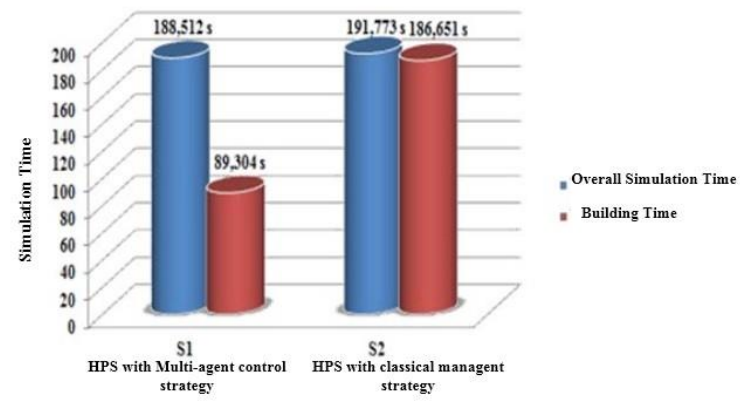

Fig. 14. Performance Comparison between two HPS models

\section{CONCLUSION}

In this paper, a design of a hybrid autonomous power system based on multi-agent approach is proposed. The system possesses a smart energy management approach that is dedicated to control the behaviour and to be fast against any encounter fluctuation. So, the presented management strategy aims to help resolving the problems related to the integration of electricity production from fluctuating renewable energy sources into the electricity supply. On the basis of the obtained simulation results, the applied strategy has proved its effectiveness and reliability to keep the optimal behaviour of the load by facilitating the communication between each constitutive element (agent interaction) which increases the integrity of the system towards any exigency. Finally, this work is performed to highlight the importance of applying multi-agents strategy, especially smart application as smart building, smart grid, smart vehicle, etc.

As a future work, we tend to test the reliability of the proposed system in real-time platform application. So, we can used several embedded platform like STM32; DSP and Raspberry in order to compare the performance of each one and lead to the most adaptable that fits perfectly with our system.

\section{ABBREVIATION LIST}

$\mathbf{Q}^{\mathbf{C}}{ }_{\text {H2 }} \quad: \mathrm{H}_{2}$ consumption amount (mol)

$\mathbf{N}_{\text {Cell }} \quad$ : Cell number of PEMFC

IERC : Cell Current of PEMFC (A)

F : Faraday coefficient $\left(96485 \mathrm{C}^{\mathrm{mol}}{ }^{-1}\right)$

$\boldsymbol{\eta}_{\mathrm{F}^{\mathrm{F}}}^{\text {ERC }} \quad:$ Faraday efficiency of PEMFC (\%)

$\mathbf{Q}^{\mathbf{P}}{ }_{\mathbf{H} 2} \quad: \mathrm{H}_{2}$ production amount (mol)

$\mathbf{N}_{\mathbf{C}} \quad:$ Cell number of Electrolyser

$\mathbf{I}_{\mathrm{ESC}} \quad$ : Cell Current of Electrolyser (A)

$\boldsymbol{\eta}_{\mathbf{F}}$ ESC $\quad$ : Faraday efficiency of Electrolyser (\%)

$\mathbf{P}_{\mathbf{T}} \quad:$ Tank pressure $(\mathrm{Pa})$

$\mathbf{P}_{\mathrm{Ti}} \quad$ : Initial tank pressure $(\mathrm{Pa})$

$\mathbf{Z} \quad$ : Compressor factor

$\mathbf{Q}_{\mathbf{H} 2}{ }^{\text {IN }} \quad:$ Input $\mathrm{H}_{2}$ Gas Amount to the Tank (mol)

R : Perfect gas coefficient $\left(\mathrm{R}=8.31 \mathrm{~J} \cdot \mathrm{Kg}^{-1} \cdot \mathrm{K}^{-1}\right)$

$\mathbf{T}_{\mathbf{T}} \quad$ : Tank temperature $\left({ }^{\circ} \mathrm{K}\right)$

$\mathbf{M}_{\mathbf{H} 2} \quad$ : Molar mass of hydrogen (g.mol $\left.{ }^{-1}\right)$

$\mathbf{V}_{\mathbf{T}} \quad:$ Tank volume (1)

$\mathbf{V}_{\text {USC }} \quad:$ Voltage of USC(V)

I $\quad:$ Current of USC (A)

$\mathbf{I}^{\mathrm{DH}}$ USC : Discharge Current of USC (A)

$\mathbf{R}_{\mathbf{S}} \quad$ : USC Resistance $(\Omega)$

C : USC Capacitance (F)

$\mathbf{V}_{\text {Usc }}(\mathbf{0}) \quad$ : USC Initial Voltage (V)

DESC, DERC, Decision Coefficients

Dusc $_{\text {US }}$

$\mathrm{SOC}_{\mathrm{H} 2}$

SOC $_{\text {USC }}$

: State of Charge of Hydrogen tank Storage (\%)

$\eta_{\text {Classical_method }}$

: State of Charge of USC (\%)

:Efficiency value calculated by classical method

APPENDIX

$\mathrm{P}_{\mathrm{SEC}}=1 \mathrm{kw}, \mathrm{Ns}=3 ; \mathrm{N}_{\mathrm{p}}=6, \mathrm{P}_{\mathrm{ERC}}=1,2 \mathrm{kw}, \mathrm{N}_{\text {cell }}=30, \mathrm{R}_{\mathrm{USC}}=25 \mathrm{~m} \Omega, \mathrm{C}=50 \mathrm{~F}$, $\mathrm{P}_{\mathrm{ESC}}=600 \mathrm{w}$.

\section{REFERENCES}

[1] K. Agbossou, M. Kolhe, J. Hamelin, and T. K. Bose "Performance of a Stand-Alone Renewable Energy System Based on Energy Storage as Hydrogen", IEEE Transactions on Energy Conversion, Vol. 19, No. 3, September 2004

[2] B.S. Sami, B.C. Abderrahmen and C. Adnane, Design and dynamic modeling of a fuel cell/ultra capacitor hybrid power system, Electrical Engineering and Software Applications (ICEESA), 2013 International Conference on “, vol.1, pp.1 - 7, March 2013.

[3] P. Thounthong, S. Pierfederici, and B. Davat, "Performance evaluation of differential flatness based-control of fuel cell/supercapacitor hybrid power source", in Proc. XIX Int Electrical Machines (ICEM) Conf, pp. $1-6,2010$.

[4] N. Bigdeli, "Optimal management of hybrid PV/fuel cell/battery power system: A comparison of optimal hybrid approaches", Renewable and Sustainable Energy Reviews, Vol.42, pp. 377-393, 2015.

[5] V. Dash and P. Bajpai, "Power management control strategy for a stand-alone solar photovoltaic-fuel cell-battery hybrid system" Sustainable Energy Technologies and Assessments, Vol. 9, pp. 68-80, 2015.

[6] M. S. Behzadi and M. Niasat, "Comparative performance analysis of a hybrid PV/FC/battery stand-alone system using different power management strategies and sizing approaches", International Journal of Hydrogen Energy, Vol. 40, pp. 538-548, 2015.

[7] M. Uzunoglu, O.C. Onar and M.S. Alam, "Modeling, control and simulation of a PV/FC/UC based hybridpower generation system for stand-alone applications", Renewable Energy, Vol. 34, pp. 509-520, 2009.

[8] Y. Ates, O. Erdinc, M. Uzunoglu and B. Vural, "Energy management of an FC/UC hybrid vehicular power system using a combined neural network-wavelet transform based strategy", International Journal of Hydrogen Energy, Vol. 35, pp. 774-783, 2010.

[9] O.C. Onar, M. Uzunoglu and M.S. Alam, "Modeling, control and simulation of an autonomous wind turbine/photovoltaic/fuel cell/ultra- 
capacitor hybrid power system", Journal of Power Sources, Vol.185, pp.1273-1283, 2008.

[10] T. Lajnef, S. Abid, and A. Ammous , "Modeling, Control, and Simulation of a Solar Hydrogen/Fuel Cell Hybrid Energy System for Grid-Connected Applications", Hindawi Publishing Corporation Advances in Power Electronics, 9 pages, 2013.

[11] M. Hadartz and M. Julander, "Battery-Supercapacitor Energy Storage",Master of Science THPS is in Electrical Engineering, Department of Energy and Environment, Division of Electric Power
Engineering Chalmers University Of Technology , Göteborg, Sweden, 2008.

[12] L. Wei, Z. Xin-jian, C. Guang-yi, "Modeling and control of a small solar fuel cell hybrid energy system", Journal of Zhejiang University Science A, Vol. 8(5), pp. 734-74, 2007.

[13] K. Zhou, J.A. Ferreira, and S.W.H. de Haan, «Optimal energy management strategy and system sizingmethod for stand-alone photovoltaic-hydrogen systems » international Journal of hydrogen Energy, Vol.33, pp.477-489, 2008. 